\title{
LA INVESTIGACIÓN ETNOGRÁFICA, UN RETO PARA COMPRENDER EL ACONTECER DEL AULA.
}

\author{
Dra. Grace Rojas Alvarado
}

Esla reflexión se circunscribe en el ámbi. to de la educación y de la invesrigación edu. cativa, la cual debe ser una práctica que se inserte en nuestra cotidaneidad y dentro de los planes de estudio.

La investigación se desarrolló mediante un enfoque einog ráfico por querer caprar esa realidad rural de una manera holistica y reconssruyendo fenómenos en sus diversos conrexros que acontecen día a día en las aulas.

La imporrancia de este ripo de investiga. cionn es incorporar a los sujeros protagonis. las en aclores principales de los procesos investigarivos.
These comments censer on the area of education and educasional research. The laner is a practice which should be part of our daily acrivities and course programs. The research was conducted using an eihnographic approach with the intention of comprehending the reality of rural areas holistically' and reconsiructing phenomena in their different contexts as they take place day' by day in the classiooms. The imporrance of this type of research is in including protagonistic subjects among the main aclors of research processes.

- Doctora en Educación por la Universidad de Costa Rica y posee estudios de maestrfa en Filosof́a y Administración Educariva. Actualmente labora como directora del Deparıamento de Análisis y Orientación de los Procesos de Enserianza y Aprendizaje del Centro Nacional de Didáctica (CENADi) del Ministerio de Educación Pública. grojas@costarricense.cr 
La práctica de la investigación debe constituirse en un pilar fundamental dentro de nuestra labor cotidiana, en las diversas esferas en que nos encontramos: como maestros y maestras en las escuelas, como docentes universitarios, como asesores y asesoras del Ministerio de Educación Pública. La investigación no sólo debe circunscribirse a los tediosos requisitos para presentar los trabajos finales de graduación, sino que debe constituirse en una práctica que se encuentre inserta en el accionar diario de los profesionales de la educación.

La investigación debe brindar herramientas cognoscitivas y afectivas para la toma de decisiones o para actuar sobre el medio y modificar aquellos aspectos que presentan problemas, a partir de un fundamento científico y no basadas en falsos supuestos o ideas preconcebidas, como suele ocurrir en nuestro ambiente educativo.

La investigación ofrece una mayor sensibilidad social, una mejor comprensión de la compleja labor de las maestras y los maestros en los diversos contexıos sociohistóricos en que se desarrollan y un acercanuiento epistemológico a los procesos mediante los cuales los sujetos aprenden y enseñan.

Es necesario considerar en los cursos que ofrecen las universidades para la formación de educadoras y educadores, la práctica de la investigación, ya que "a investigar se aprende investigando". Si bien sabemos que se aprende a través de modelos, es importante que los educadores y educadoras enseñemos a nuestros estudiantes a investigar e incorporamos en las investigaciones de ellos. Sólo de esta manera se logra realizar una ruptura epistemológica entre educador-educando, para convertir esa relación en un diálogo de aprendices.

Quiero relacionar esta ponencia, con mi experiencia dentro del Programa de Doctorado en Educación de la Unniversidad de Costa Rica, cuando desde los inicios del mismo, me propuse realizar una investigación en el contexto rural costarricense, que me permitiera hacer algo diferente a lo que en algún momento hicimos, embuidos en un paradigma positivista de investigación.

Quería acercarme a la realidad rural para conocerla y encontrar significados que me permitieran valorar lo que se hace en ella, desde la particularidad que ofrece el contexto rural. Por lo anterior, me propuse trabajar mediante el enfoque etnográfico, que se enmarca dentro de la visión cualitativa de la investigación. En nuestro país, la mayor parte de estos estudio han sido realizados por antropólogos, quienes desde una manera muy creativa han venido dejando constancia escrita de sus experiencias.

A pesar de los esfuerzos anteriormente citados, todavía en nuestro país es muy incipiente la investigación etnográfica, contrario a lo que se ha realizado en México, sobre todo, en el Centro de investigación y de Estudios Avanzados del Instituto Politécnico Nacional, también ha incursionado Colombia y Brasil, a partir de los trabajos de Paulo Freire. 
La etnografía es la ciencia que tiene por objeto el estudio y la descripción de las razas o pueblos. La etnografía es un proceso, una forma de estudiar la vida humana. El diseño etnográfico requiere estrategias de investigación que conducen a la reconstrucción cultural.

La investigación etnográfica posee un carácter holista, pretende reconstruir descripciones de fenómenos en sus diversos contextos y determinar a partir de ellas, las complejas conexiones de causas y consecuencias que afectan el comportamiento de los sujetos.

El objeto de la etnografía se centra en descubrir, es decir, poner en cvidencia lo que acontece cotidianamente en las aulas, con el propósito de aportar datos significativos de la forma más descriptiva posible, para luego interpretarlos y comprender en forma adecuada en ese nicho ecológico que son las escuelas.

\section{Aspectos que se deben tomar en cuenta para la realización de una investi- gación etnográfica}

Clifford Geertz plantea que la etnografía es oficio de lugar, trabaja a la ley del conocimiento local, por lo anterior es que el etnógrafo debe conocer la importancia de establecer una relación prolongada con las personas que desea investigar. En el caso particular de mi investigación fueron aproximadamente nueve meses en el campo, compartiendo con niños, niñas, maestros y maestras la cotidianidad, el ingreso a la escuela a las 7 a.m., el almuerzo de las 12 a.m., los recreos, los actos cívicos, los juegos de los niños $Y$ las niñas, las conversaciones de los maestros y las maestras, las reuniones con madres y padres, las visitas a los más antiguos pobladores de la comunidad. Todas estas voces de los sujetos constituyen la riqueza de un estudio etnográfico.

\section{La negociación de entrada}

Establecer la negociación de entrada a la institución, es un requisito indispensable para quien desee investigar. En el caso particular de mi investigación, en primer lugar, conversé con la supervisora del circuito escolar, posteriormente ella me comunicó que había una directora interesada. Decidí visitarla y ella con mucha claridad me preguntó: ¿Qué iba a ganar la escuela con mi investigación? ¿Cómo beneficiaría a los educadores y las educadoras de la institución? Yo le respondí que los primeros en conocer los datos de la investigación iban a ser ellos y ellas y que me comprometía a reunirlos una vez que tuviera suficientes datos. 
Una negociación en el campo no es suficiente, también hay que establecerla de manera diferente con los niños y las niñas, miembros de la comunidad, madres y padres, entre otros.

Los maestros se sentían muy incómodos cuando eran observados, este constituye uno de los aspectos más delicados dentro de la investigación etnográfica. En cambio, los niños y las niñas se sentían muy a gusto y puedo decir que fue a través de ellos y ellas, que los maestros me aceptaron.

\section{La recolección de las voces de los protagonistas}

Las voccs de los sujetos se recogieron mediante entrevistas, observaciones participantes y no participantes, análisis de documentos: actas, planeamientos, monografías, entre otros. Con todos los datos recolectados en diarios de campo, se procedió a codificar la información después de realizar múltiples lecturas diarias sobre lo que informan los sujetos.

En esta perspectiva, los principales informantes se convierten en lo que en sentido filosófico Fornet-Betancourt $(1994,19)$,plantea que no se trata de convertir nuestra propia manera de pensar en el lugar de encuentro con el otro, es decir, no hacer de nuestro mundo categorial el centro desde el cual nosotros "comprendemos" al otro, en el sentido de definirlo y determinarlo a la luz de nuestro horizonte de comprensión. Ese "entender" asimila e incorpora por reducción, pero no se cumple como conocimiento que reconoce en el otro una fuente de sentido de igual originalidad y dignidad. Por ello debemos ganar el acceso a los otros no desde nuestro propio modo de pensar, sino desde la situación histórica del encuentro con él otro y con las otras.

El encuentro con el otro es así interpelación, desde la que debería ser repensada nuestra manera de pensar, pues en esa situación experimentamos que hay otro horizonte de comprensión que nosotros no fundamos y que, por eso mismo nos desafía como una posibilidad de respectivizar nuestra propia posición original.

\section{La codificación de la información}

La información se agrupa mediante diversos códigos que establece el investigador o la investigadora para luego proceder a diseñar categorías de análisis, los resultados se representan mediante un género especial de texto, que describe densamente como menciona Geertz (1987), la particularidad del lugar, y a la vez, la haga inteligible ubicándola dentro de la discusión teórica. 
Lo esencial en la experiencia

etnográfica radica en la

posibilidad de transformarnos a

nosotros mismos, es decir,

transformar nuestras concepciones

acerca de otras visiones de mundo

$y$ con base en esa información

producir conocimientos

El investigador o la investigadora, cuando ingresa al campo, posee una serie de creencias en cuanto a lo que quiere observar, también se incorpora con una serie de elementos teóricos respecto del objeto de estudio. Sin embargo, en la investigación etnográfica se realimentan constantemente lo encontrado en el campo y lo que informa la teoría sobre las concepciones, ideologías y creencias en relación con el objeto de estudio.

No obstante, las creencias iniciales se modifican en el transcurrir de la investigación. La relación estrecha que se establece entre teoría y práctica es lo que va modificando las creencias con las cuales el investigador o investigadora se incorporó al campo.

\section{Devolución de la información}

Otro aspecto fundamental dentro de la investigación etnográfica lo constituye la devolución de la información recopilada a los sujetos que han participado de la investigación. Este es un aspecto muy delicado e implica un compromiso ético del investigador o la investigadora. No obstante lo anterior, representa una gran riqueza en el proceso investigativo, porque plantea disonancias cognitivas a los protagonistas de la investigación y puede que ellos se concienticen en relación con su papel como educadores y se pueden visualizar desde una nueva perspectiva.

\section{La triangulación de la información}

Un aspecto muy importante en la investigación etnográfica lo constituye la triangulación. Este proceso permite confrontar los datos en las siguientes perspectivas:

Triangulación de datos: implica el uso de varias fuentes de datos en el estudio, los datos se obtuvieron en las diferentes técnicas de recolección de información.

Triangulación metodológica: se establece mediante la incorporación de varias técnicas para obtener los datos, entre las que tenemos: la entrevista, la observación participante, instrumento, entre otras. 
Triangulación del investigador: se refiere al proceso de triangulación con participación de otros investigadores, con quienes se comparten la información recopilada.

Triangulación de la teoría. Cuando el investigador o la investigadora ingrcsa al campo, posee determinado marco referencial sobrc el objeto de estudio, dicho referencial va modificándose mediante la lectura de diversos autores que tratan la temática. Todo lo anterior va conformando un referencial tcórico que adopta el investigador.

\section{IMPORTANCIA DE LA INVESTIGACIÓN ETNOGRÁFICA}

Entre los aspectos más importantes que se obtienen a partir de la investigación etnográfica están:

Lo esencial en la experiencia etnográfica radica en la posibilidad de transformarnos a nosotros mismos, es decir, transformar nuestras concepciones acerca de otras visiones de mundo y con base en esa información producir conocimientos. Lo anterior, se logra mediante el diálogo con otros sujetos que intentan transformar o conservar su entorno social y cultural (Rockwell, 1994).

Otro aspecto importante de mencionar en la investigación etnográfica es que permite tomar decisioncs científicas a partir de ellas. Además, incorpora a los sujetos protagonistas en actores principales de los procesos investigativos, dando como resultado un proceso constructivo en que se involucran tanto investigador como investigados.

Como investigadores e investigadoras tenemos la obligación de dejar constancia escrita de lo que aprendemos, sin embargo, muchos de los aspectos que aprendimos y compartimos en el proceso de la investigación quedan inexorablemente escritos en nuestras almas. para luego compartirlos con otras almas interesadas.

\section{Referencias}

Fornet-Betancourt, R. (1994) Hacia una filosafia insercultural latinoamericana. Editorial DEI, San José

Goetz, J. P. y Lecompte, M. D. (1983) Etmografia y diseño cualitativo en investigación educativa. Ed. MORATA, Madrid.

Rockwell, Elsie (1994) La etnografía como conocimiento local en La etnografia en Educacion. Panorama. Prácticas y Problemas. Centro de Investigaciones y Servicios Educativos UNAM, México. 
Rojas, G. (2002) Creencias que construyen los sujelos que participan en el desarrollo de los procesos de aprendizaje yenseñanza en una escuela de primaria. Tesis presentada en la Universidad de Costa Rica. 